\title{
Compreensão dos riscos ergonômicos a partir da percepção e função dos motoristas de caminhões em uma empresa na cidade de Itabira - MG
}

Understanding of ergonomic risks from the perception and function of truck drivers in a company in the city of Itabira - MG

\author{
Alessandra Monteiro Assis 1,*; Shirlei Luana Chaves e Souza Pereira²; Patricia Carla de Brito \\ Neves ${ }^{3}$ \\ 1, 2, 3 Fundação Comunitaria de Ensino Superior de Itabira, Itabira, MG, Brasil. \\ *amassis200278@yahoo.com.br
}

\begin{abstract}
Resumo
Este trabalho foi resultante de uma pesquisa que teve como proposta analisar a percepção da função de motorista de caminhão em uma empresa na cidade de Itabira MG aos riscos ergonômicos expostos. O método utilizado foi a Análise Ergonômica do Trabalho (AET), consistindo no levantamento do perfil dos motoristas seguido de uma avaliação ergonômica do posto de trabalho da função de motorista de caminhão; posteriormente descreveu-se a postura adotada pelo motorista na execução da sua atividade e, por fim, a identificação da percepção dos motoristas quanto aos riscos ergonômicos existentes na atividade desempenhada. Neste estudo adotou-se a pesquisa de caráter descritivo, com abordagem qualitativa e o método foi de uma pesquisa de campo. Como instrumentos de coleta de dados foram utilizados os métodos observacionais e a aplicação de um formulário aos motoristas de caminhão. O universo do estudo foi uma empresa responsável pelo recolhimento do lixo na cidade de Itabira MG, tendo como foco amostral a Gerência de Transporte e Manutenção da empresa a partir do critério de amostragem não probabilística por tipicidade e acessibilidade. O tratamento dos dados foi realizado por meio da análise de conteúdo resultante da aplicação do formulário e da observação direta. O resultado obtido do estudo permitiu a identificação dos principais riscos ergonômicos do posto de trabalho de motorista de caminhão: calor excessivo, ruído intenso e a presença de vibração ocupacional.
\end{abstract}

Palavras-chave: Análise Ergonômica do Trabalho, Percepção dos Motoristas, Risco Ergonômico.

This work resulted of a research that analyzed the perception of the truck driver function in a company in the city of Itabira - MG to exposed ergonomic risks. The method used was Ergonomic Work Analysis (EWA), consisting of the survey of the profile of the drivers, followed by an ergonomic evaluation of the job position of the truck driver function, later described the posture adopted by the driver in the execution of the their activity and, finally, the identification of the drivers' perception of the ergonomic risks that exist in the activity performed. In this study we adopted the descriptive research, with a qualitative approach and the method was field research. Observational methods and the application of the form to truck drivers were used as instruments of data collection. The universe of this study was a company responsible for garbage collection in the city of Itabira - MG, having as sample the Transport and Maintenance Management of the company, based on non-probabilistic sampling criteria for typicity and accessibility. The treatment of the data was performed through content analysis of the application of the form and direct observation. The result obtained from this study identified that the main ergonomic risks of truck driver work are: excessive heat, intense noise and the presence of occupational vibration.. 


\section{INTRODUÇÃO}

A ergonomia vem assumindo um papel relevante no ambiente de trabalho que envolve a relação do trabalhador com as várias tecnologias presentes nesse ambiente. Ela favorece a segurança e saúde dos trabalhadores, garantindo eficiência do trabalho, satisfação e conforto, entretanto, diminuindo problemas que podem causar acidentes ou doenças ocupacionais. Comumente, a análise dos acidentes de trabalho demonstra a relação de posto de trabalho inadequado com o biótipo do trabalhador e as necessidades de qualidade e maior produtividade.

A Análise Ergonômica do Trabalho (AET) pode contribuir de forma significativa na qualidade de vida do trabalhador e na segurança do trabalho por meio de melhorias nas condições de trabalho e alterações no processo produtivo dos trabalhadores. A prevenção de acidentes e doenças ocupacionais pode ser alcançada em decorrência da AET, que visa o levantamento dos riscos ergonômicos.

A preocupação com as questões ergonômicas vem aumentando nas últimas décadas quando cada vez mais os postos de trabalho vêm sendo planejados e desenvolvidos considerando-se as necessidades do trabalhador. A multidisciplinaridade da ergonomia faz com que diversos setores sejam favorecidos com os benefícios da análise ergonômica de forma eficaz e integral.

Os atuais avanços e tecnologias promovem necessidades de trabalhos e serviços cada vez mais rápidos e produtivos, demandando pessoas que estejam alocadas em ambientes de trabalho de maneira confortável e seguras. A ergonomia vem assumindo um papel relevante relacionando o trabalhador com as diversas tecnologias presentes nos ambientes laborais, favorecendo a segurança e a saúde dos trabalhadores, garantindo a eficiência do trabalho, a satisfação, o conforto e diminuindo ainda os riscos de acidentes ou doenças ocupacionais.

É nesse contexto que se insere o presente estudo, com o objetivo de avaliar ergonomicamente o posto de trabalho do motorista de caminhão em uma empresa na cidade de Itabira - MG, a partir das observações em campo, e identificar os riscos ergonômicos da função sob a ótica desses motoristas, descrevendo ainda a postura adotada pelos mesmos na execução da sua atividade.

\section{Metodologia}

Neste trabalho adotou-se a pesquisa de caráter descritiva com uma abordagem qualitativa, tendo como método a pesquisa de campo. O universo da pesquisa foi uma empresa que é responsável pelo recolhimento de lixo na cidade de Itabira - MG, tendo como foco amostral a Gerência de Transporte e Manutenção da empresa. O número total de trabalhadores dessa gerência é de 50 trabalhadores, dentre eles 25 motoristas de caminhões.

A partir da pesquisa na literatura científica, deu-se início a coleta de dados para, em seguida, se avaliar as condições de trabalho, segurança no trabalho, saúde do trabalhador e a percepção dos motoristas quanto aos riscos ergonômicos e, posteriormente, se analisar os dados obtidos por meio da pesquisa de campo e da observação direta. 


\section{Resultados e Discussão}

Este tópico apresenta a análise dos dados obtidos, fundamentada na literatura científica pesquisada. A partir da coleta de dados, avaliou-se as condições de trabalho, segurança no trabalho, saúde do trabalhador e a percepção dos motoristas quanto aos riscos ergonômicos.

O conhecimento do perfil dos motoristas de caminhão e a percepção destes são de fundamental importância para melhoria nas condições do ambiente de trabalho. Todos os entrevistados possuem a função de motorista, são do sexo masculino, trabalham no período diurno com carga horária de 44 horas semanais e intervalo de intrajornada de 1 hora/dia.

Os dados relacionados quanto ao aspecto de estrutura corporal (peso e altura) foram informados pelo próprio entrevistado. O Índice de Massa Corporal (IMC) foi calculado utilizando-se o Microsoft Excel. Os dados obtidos estão apresentados na Tabela 1.

Tabela 1 - Perfil dos motoristas de caminhão.

\begin{tabular}{l|l|l|l}
\hline Variáveis & Mínimo & Máximo & Média \\
\hline Idade (anos) & 36 & 68 & 52 \\
Peso (kg) & 67 & 108 & 84 \\
Altura (m) & 1,63 & 1,86 & 1,74 \\
IMC & 21 & 37 & 27 \\
Tempo de empresa (anos) & 1 & 30 & 13 \\
Tempo de profissão (anos) & 7 & 43 & 24 \\
\hline
\end{tabular}

Fonte: Elaboração própria (2017).

Por meio da análise do perfil dos motoristas de caminhão foi possível evidenciar algumas particularidades desse grupo: a predominância do sexo masculino, faixa etária entre 36 e 68 anos e o tempo de profissão são características interindividuais, ou seja, alguns estão a mais tempo exercendo a função de motorista do que outros (tempo variou de 7 a 43 anos de profissão). No próximo tópico será apresentada a análise ergonômica do posto de trabalho.

\subsection{Análise ergonômica}

Com o propósito de responder aos objetivos da pesquisa, foi realizada a análise ergonômica do posto de trabalho dos motoristas de caminhões do pátio da Gerência de Transporte e Manutenção da Empresa, entre os dias 30 de março e 22 de abril de 2017, quanto ao acesso à cabine, assento, visibilidade e projeto interno do veículo.

Couto (1995) afirma que a análise macroscópica possibilita uma visão ampla do posto de trabalho, sendo analisado o arranjo físico (layout), a postura e os movimentos do trabalhador, o levantamento, o transporte e a descarga individual de materiais. om base nessa visão, o presente tópico apresenta a análise macroscópica do posto de trabalho do motorista de caminhão.

As atividades desenvolvidas pela empresa pesquisada envolvem o recolhimento do lixo da cidade de Itabira - MG e municípios vizinhos. Para a realização desse processo de 
recolhimento a empresa conta com uma frota composta dos seguintes veículos fabricados em 2014: Iveco Tector, Ford Cargo e Volvo VM-270 4x2, como mostra a Figura 1.

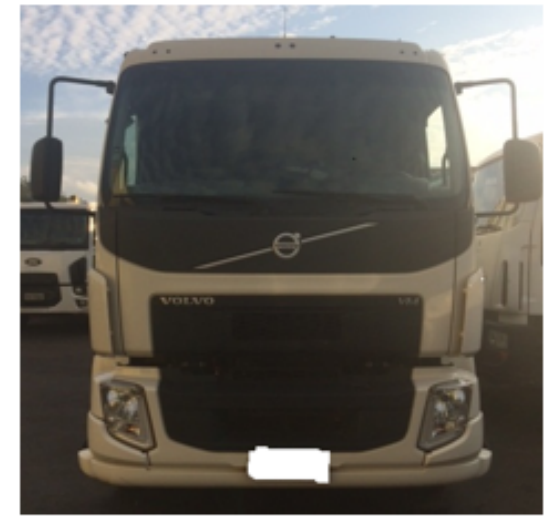

Volvo VM-270 $4 \times 4$

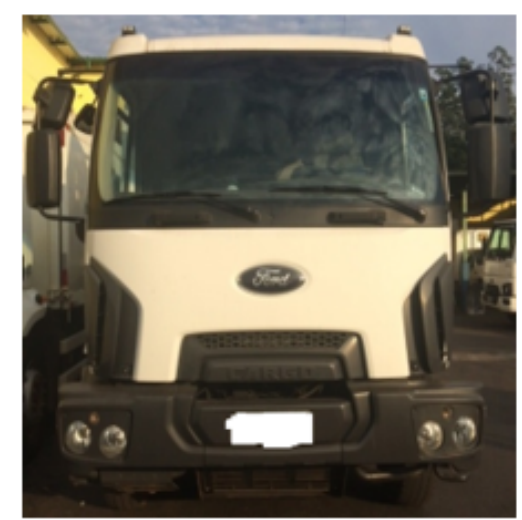

Ford Cargo

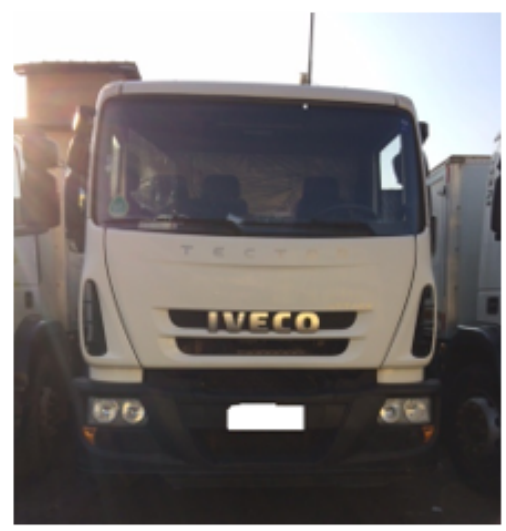

IvecoTector

Figura 1 - Frota de caminhões.

Fonte: Acervo pessoal (2017).

O design da cabine de todos os veículos analisados possibilita uma boa visibilidade ao motorista de toda a extensão do veículo. Os parabrisas possuem uma configuração ampla e os retrovisores são grandes e com regulagem interna; todos com excelente visibilidade, minimizando as áreas cegas. Possuem janelas laterais envidraçadas na cor branca transparente. O posto de trabalho possui dois lugares para transporte de passageiros mais o assento do motorista. Para Kilesse (2005), a boa visibilidade para o motorista evita que esse assuma posturas inadequadas e incorretas para visualizar a parte externa da cabine, evitando o risco de acidentes de percurso.

A Figura 2 apresenta a imagem do assento de um dos veículos utilizados pelos motoristas da empresa em estudo. 


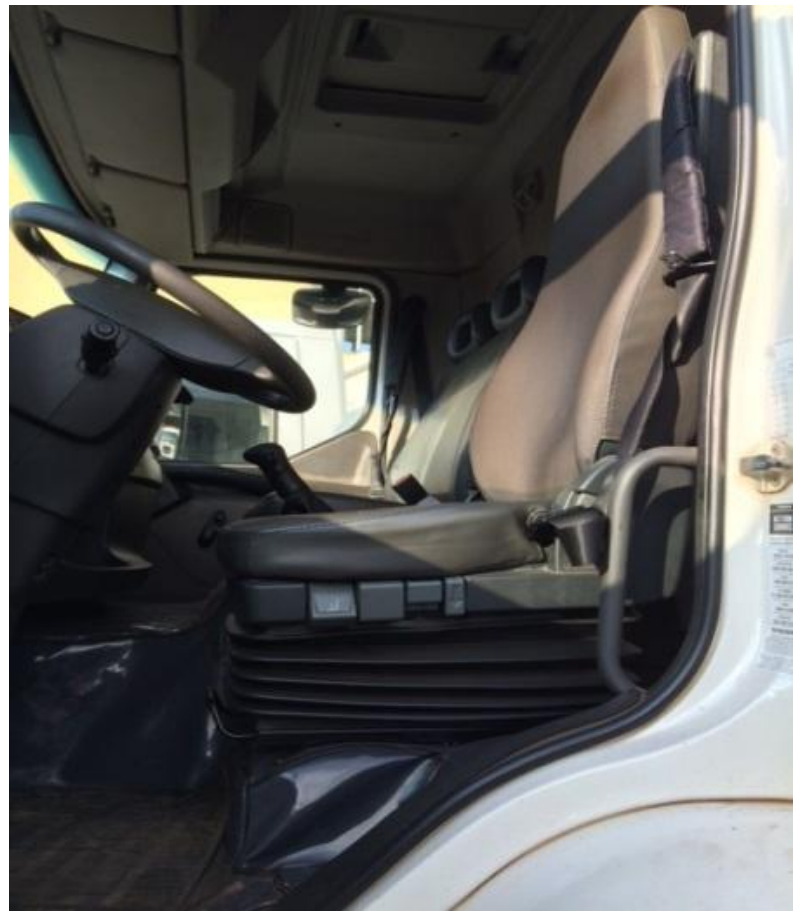

Figura 2 - Assento.

Fonte: Acervo pessoal (2017).

Observa-se na Figura 2 que os assentos de possuem regulagem de altura e inclinação de aproximação, para frente e para trás, e os controles para essas regulagens são fáceis de acessar e manipular; o encosto do assento permite variações de postura e o estofamento apresenta um ótimo estado de conservação e higienização.

De acordo com Iida (2005) a postura sentada exige uma atividade da musculatura dorsal em conjunto com a musculatura ventral para sustentar esta posição. Particularmente, quase todo o peso do corpo é suportado pelas tuberosidades isquiáticas, por isso, o assento deve possibilitar mudanças frequentes de posturas, para protelar o sentimento de fadiga. Faria (2013) completa dizendo que o assento é o maior causador de lombalgia em motorista e que muitos veículos não preenchem as condições mínimas para o conforto.

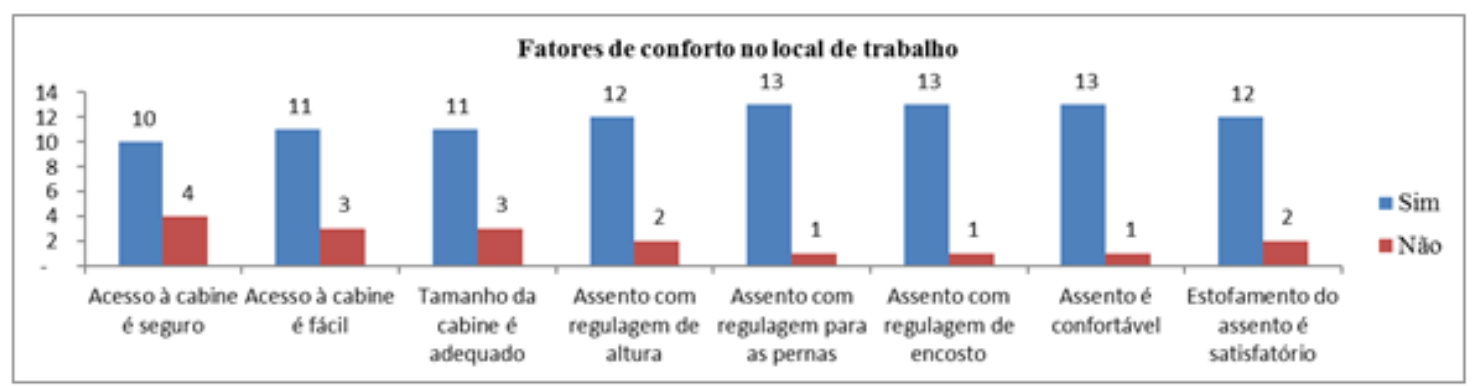

Gráfico 1 - Fatores de conforto no local de trabalho.

Fonte: Elaboração própria (2017).

O Gráfico 1 evidenciou que o assento é confortável e possui todas as regulagens adequadas para o melhor uso dos motoristas. Em nenhum dos caminhões analisados foi 
encontrado acessórios para o assento como apoio lombar e ou suporte lombar, isso significa que os motoristas acham que os assentos são adequados. Pode-se verificar que 11 motoristas consideraram a cabine de fácil acesso e de tamanho adequado e quatro disseram que o acesso à cabine não é seguro. Apenas dois motoristas consideraram que o estofamento do assento é insatisfatório.

O dimensionamento da cabine e as variáveis de acesso e assento dos caminhões foram avaliados qualitativamente, por meio do formulário aplicado aos motoristas, e quantitativamente, por medição direta utilizando-se uma trena graduada com precisão de um centímetro, conforme indicado na Tabela 2.

Tabela 2 - Dimensionamento da cabine.

\begin{tabular}{l|c|l|c}
\hline & $\begin{array}{l}\text { Ford } \\
\text { Cargo }\end{array}$ & $\begin{array}{l}\text { Iveco } \\
\text { Tector }\end{array}$ & $\begin{array}{l}\text { Volvo } \\
\text { VM 4X2 }\end{array}$ \\
\hline Distância da cadeira ao painel & $88 \mathrm{~cm}$ & $78 \mathrm{~cm}$ & $76 \mathrm{~cm}$ \\
Distância da cadeira ao volante (direção) & $66 \mathrm{~cm}$ & $64 \mathrm{~cm}$ & $68 \mathrm{~cm}$ \\
$\begin{array}{l}\text { Distância da janela à esquerda ao câmbio de } \\
\text { marcha }\end{array}$ & $78 \mathrm{~cm}$ & $75 \mathrm{~cm}$ & $75 \mathrm{~cm}$ \\
Distância do assento ao teto & $80 \mathrm{~cm}$ & $118 \mathrm{~cm}$ & $119 \mathrm{~cm}$ \\
\hline
\end{tabular}

Fonte: Elaboração própria (2017).

A direção dos veículos é hidráulica, os volantes são reguláveis tanto no sentido vertical quanto no horizontal, os câmbios não são automáticos, mas são macios e possibilitam trocas curtas de marchas. Todos os entrevistados responderam que as informações do painel e mostradores (display) são organizadas, de simples leitura e objetivas, os controles de acesso são facilmente alcançáveis; verificou-se a presença de extintores de incêndio e não foi observada a presença de tacógrafo. Esses veículos não são adaptados para pessoas com necessidades especiais já que não possuem plataformas elevatórias que abaixa até o nível do piso da calçada para facilitar o acesso. Após a realização da análise ergonômica descreveu-se a postura adotada por eles durante a execução da sua atividade.

\subsection{Postura de trabalho adotada pelo motorista na execução da sua atividade}

$\mathrm{A}$ atividade do motorista inicia-se às $07 \mathrm{~h} 30 \mathrm{~min}$ quando ele se desloca até $\mathrm{o}$ veículo que fica estacionado no pátio da empresa analisada. Ele preenche um checklist fornecido pela empresa para identificar alguma irregularidade; logo após a vistoria, não havendo irregularidades nos compartimentos do veículo, ele dá continuidade à sua atividade dirigindo até o caminhão e sentando-se em sua poltrona a regula de acordo com a sua coluna vertebral. O caminhão, então, é deslocado para as ruas em direção à rota estabelecida pela empresa. Os movimentos realizados nos membros inferiores exigem uma coordenação com os membros superiores e dinamismo do motorista. Esses movimentos são acompanhados de olhares rápidos e precisos em direção aos retrovisores laterais e internos que objetivam a atenção ao conduzir o veículo. O membro superior direito trabalha em sincronia com o membro inferior esquerdo durante os movimentos de mudanças de marcha.

Durante a atividade do motorista de caminhão, Kilesse (2005) afirma que todo o corpo (cabeça, tronco, membros superiores e inferiores) é solicitado e requisitado de forma coordenada durante a realização das atividades pois no pequeno espaço em que o motorista 
realiza suas atividades, a posição sentada e a atenção nos mostradores do painel e nos controles fazem com que o motorista conduza o veículo corretamente.

Ao analisar a postura do motorista durante sua atividade pode-se observar que ele assume uma postura predominantemente sentada e exerce movimentos de flexão e extensão da cabeça, flexão estática do ombro, inclinação e rotação do tronco, movimentos de flexão e extensão de cotovelo no instante de passar marcha, flexão estática dos joelhos devido à postura sentada, frequentes movimentos dos tornozelos no momento de pisar na embreagem, aceleração, frenagem, combinação de coordenação visual, auditiva e raciocínio rápido para executar sua tarefa, como retratada na Figura 3.

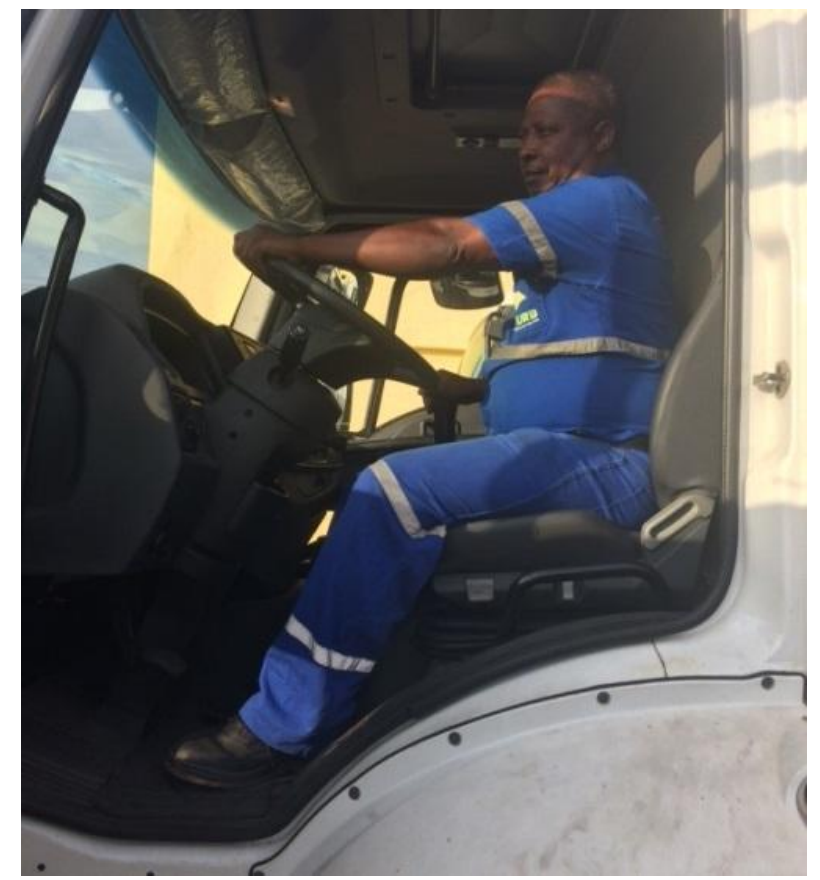

Figura 3 - Exigências psicomotoras.

Fonte: Acervo pessoal (2017).

Segundo Queiróga e Michels (1999), a profissão de motorista exige repetições de movimentos nos membros superiores e inferiores para dirigir um veículo, no entanto, não se conhece o quanto essas ações são maléficas para estes segmentos corporais. Esses mesmos autores afirmam que devido a tarefa ser exercida na posição sentada com constantes rotações do pescoço e inclinações no tronco superior, as sobrecargas maiores são percebidas na coluna vertebral.

De acordo Battiston et al. (2006) os movimentos repetitivos dos membros superiores durante o trabalho provocam sobrecarga muscular, lesão, dor e fadiga muscular. Os aspectos orgânicos e psicológicos do motorista, juntamente com a carga de trabalho estática e dinâmica, além de um ambiente agressivo e insatisfatório se unem para o aparecimento da fadiga muscular. O aparecimento de dor, contraturas e lesão são aspectos de cronicidade da fadiga muscular, tornando um ciclo vicioso de dor.

Dessa forma, a profissão de motorista faz-se estressante e fatigante por causa do estado de atenção e alerta que o profissional deve ter constantemente, da postura que deve permanecer e dos atos repetitivos que deve realizar. Essas situações propiciam à profissão de motorista algumas doenças ocupacionais que em muitos casos levam a irritabilidade, 
estresse, fadiga, absenteísmo e até mesmo a aposentadoria precoce.

O Gráfico 2 mostra o resultado da questão que trata da percepção dos motoristas quanto à dor (ou desconforto) decorrente da sua atuação profissional. Dentre os entrevistados, 11 respondentes relataram sentir dor e ou desconforto e apenas 3 não se apontaram sentir dor.

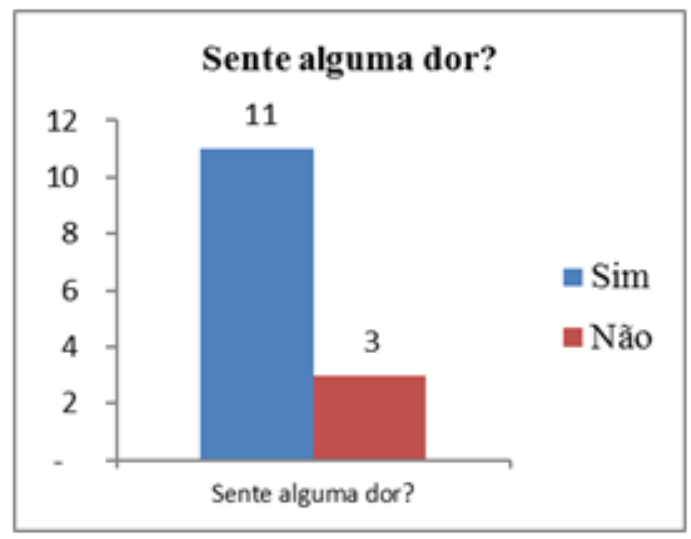

Gráfico 2 - Sente alguma dor (ou desconforto).

Fonte: Elaboração própria (2017).

Ainda tratando da questão da dor (ou desconforto), a pesquisa procurou inferir a intensidade desse efeito para também inferir a gravidade da dor (ou desconforto) dos motoristas respondentes, conforme representado no Gráfico 3.

\section{Classificação da dor}

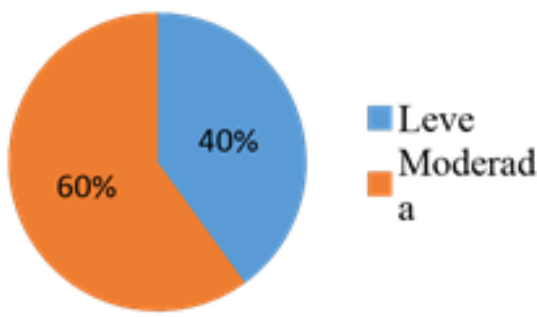

Gráfico 3 - Classificação da dor.

Fonte: Elaboração própria (2017).

Por meio do Gráfico 3 pode-se afirmar que dos 11 entrevistados que relataram dor (ou desconforto), a maior parte (60\% desses motoristas) classificou-a como moderada. Por fim, a última característica analisada foi ao tempo de aparecimento da dor, nota-se que todos os motoristas sentem dor acima de seis meses, tornando assim uma dor crônica.

Pode-se concluir que a postura adotada pelo motorista durante a execução da sua atividade é predominantemente sentada, com combinação dos movimentos dos membros superiores e inferiores associados a constantes rotações do pescoço e inclinações no tronco 
superior, ocasionando sobrecarga na coluna vertebral. Os movimentos repetitivos no membro superior, juntamente com o ambiente insatisfatório causa sobrecarga muscular levando a dor e fadiga muscular. A dor foi uma característica presente em 11 dos entrevistados, classificando-a como moderada e com tempo acima de seis meses, levando à cronicidade do quadro.

De acordo com o Instituto da Mobilidade e dos Transportes (IMT, 2016), o motorista expõe-se a agentes ambientais ocupacionais, físicos e organizacionais que são os principais responsáveis por causar efeitos nocivos à saúde desses trabalhadores.

Todos os caminhões interiormente possuem ventilação natural vindo das janelas laterais, do teto e dos sopradores simples, presença de alavanca de emergência, o piso é antiderrapante e a iluminação é natural durante o dia e por meio de lâmpadas fluorescentes no período noturno, como ilustrado na Figura 4.

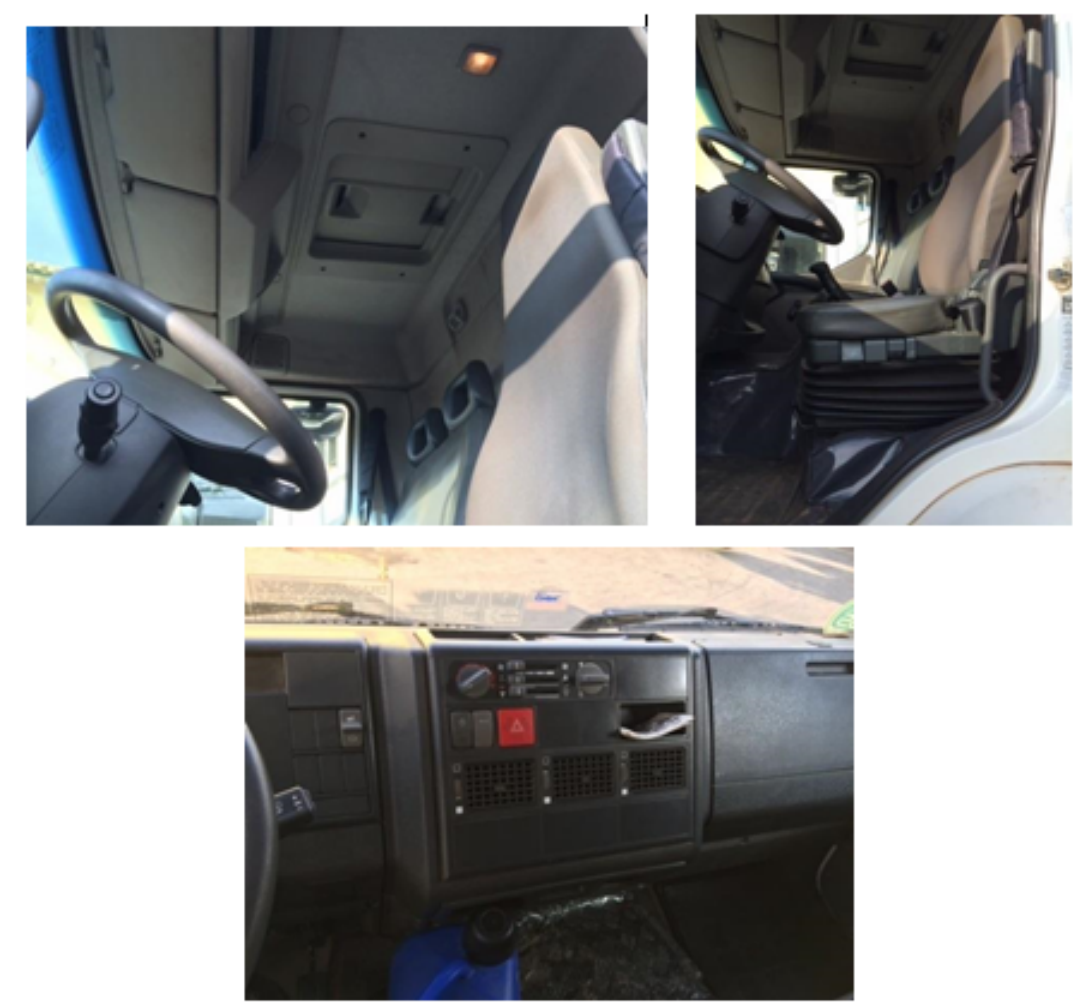

Figura 4 - Interior dos caminhões. Fonte:acervo pessoal (2017).

Diversas características do veículo podem influenciar exatamente na qualidade de conforto: o assento, a higiene e segurança, o espaço interno, as dimensões das portas, os apoios, a altura dos degraus, a visibilidade e os riscos ambientais como conforto térmico, presença de vibração e iluminação.

O conforto térmico dentro da cabine do caminhão, o nível de ruído, a presença de vibração e a iluminação foram avaliados qualitativamente por meio do formulário aplicado e respondido pelos motoristas. Os resultados obtidos estão demonstrados no Gráfico 4 a seguir. 


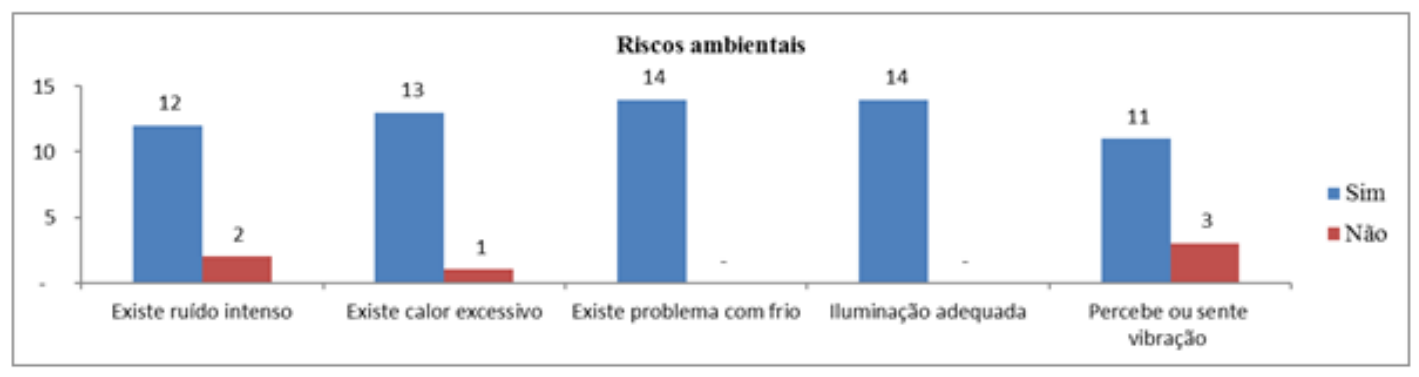

Gráfico 4 - Avaliação qualitativa dos agentes ambientais.

Fonte: Elaboração própria (2017).

Observa-se no Gráfico 4 a presença do desconforto térmico (temperatura elevada) dentro da cabine pelos motoristas. De acordo com Santos et al. (2009) a temperatura elevada afeta a atividade dos motoristas alterando seu humor, deixando-o mais irritado e agressivo. A alta temperatura prejudica o desempenho de dirigir, ficando desatento e sonolento. Por fim, Kroemer e Grandjean (2008) afirmam que a conservação de uma temperatura confortável é fundamental para o bem-estar e melhor produtividade do trabalhador.

A análise dos resultados do Gráfico 4 evidenciou que a presença do ruído percebido pelos motoristas é intensa. Kroemer e Grandjean (2005) define ruído como um som desagradável e que perturba, e se esse for de alta frequência levará a danos a saúde do trabalhador como fadiga, mal-estar, irritabilidade e até Perda Auditiva Induzida por ruído (PAIR). Esses autores afirmam que um dos efeitos do ruído no organismo humano é a queda da produtividade observada em atividades que requer concentração mental e precisão dos movimentos. Para Suter (2016) os trabalhadores são submetidos aos danos causados pelo ruído devido à ausência de programas preventivos.

Ainda sobre Gráfico 4, observou-se que grande parte dos motoristas relataram que perceberam ou sentiram vibrações dentro da cabine. Segundo Sebastião et al. (2007), a vibração ocupacional é um fator de risco à saúde do motorista e pode trazer sérias sequelas ao organismo humano. Estudos com motoristas de caminhão e de ônibus descrevem que esses trabalham sob níveis de vibração inadequado e, potencialmente, nocivos à saúde, em consequência de assentos inadequados, trepidação devido às irregularidades nas ruas e rodovia, tipo de amortecedor do veículo, estado de manutenção do veículo dentre outros, o que ocasiona danos à coluna vertebral. As vibrações mecânicas são transmitidas aos discos intervertebrais que funcionam como amortecedores de impactos sofridos pela coluna vertebral, entretanto, se essa condição for contínua, acarreta redução da eficácia nos movimentos da coluna vertebral (QUEIRÓGA, 2002). Silva e Mendes (2005) descrevem que a exposição à Vibração no Corpo Inteiro (VCI) traz consequências desfavoráveis à coluna vertebral, como degeneração precoce da região lombar, hérnia de disco e lombalgia.

Todos os motoristas consideraram a iluminação adequada dentro do caminhão, conforme mostrado no Gráfico 4. Robin (1987) apud Kilesse (2005) sugere que a iluminação do painel que se encontra no interior do veículo, seja visível e não incomode ao motorista. A fadiga visual pode trazer consequências ao trabalho como o aumento das falhas e acidentes de trabalho, diminuição da produção e da qualidade do trabalho (GRANDJEAN, 1998). O Gráfico 5 verifica a presença dos fatores de climatização no local de trabalho. 


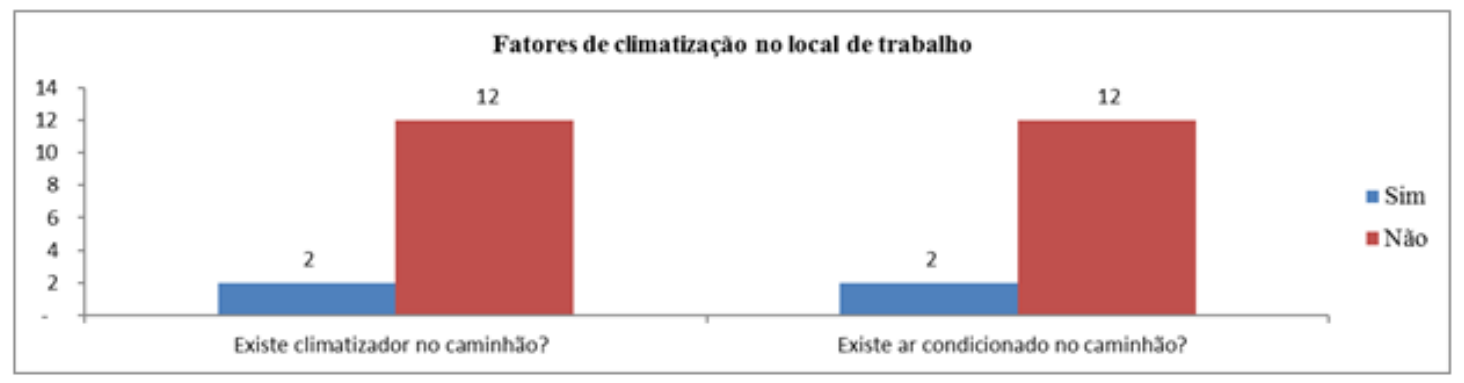

Gráfico 5 - Condições de Climatização no posto de trabalho.

Fonte: Elaboração própria (2017).

Pode-se observar no Gráfico 5 que 12 entrevistados disseram não existir ar condicionado e climatizador na cabine dos caminhões. Os 11 motoristas que relataram sentir dor e ou desconforto (Gráfico 2) foram questionados quanto à localização da sua dor, como mostra o Gráfico 6.

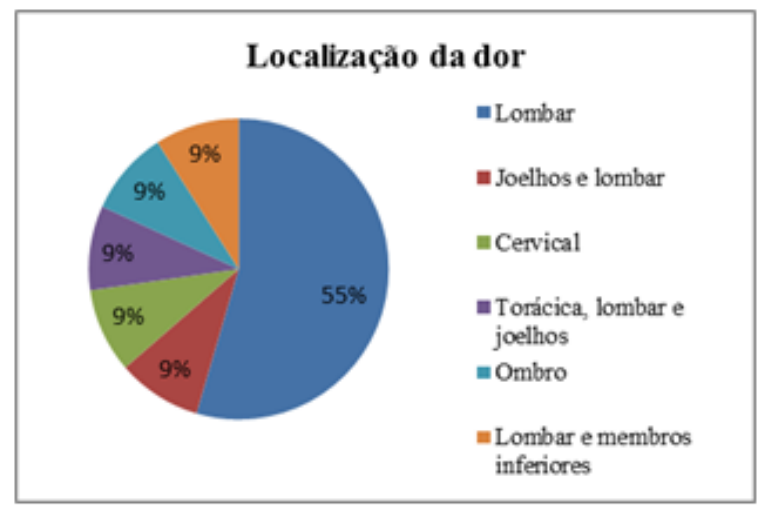

Gráfico 6 - Localização da dor.

Fonte: Elaboração própria (2017).

Pode-se observar no Gráfico 6 que 55\% dos motoristas que relataram sentir dor ou desconforto, indicaram a região do dorso inferior (região lombar) como a região mais dolorida, acompanhada posteriormente com $9 \%$ as regiões do joelho e lombar, $9 \%$ a região cervical, $9 \%$ as regiões torácica, joelhos e lombar, $9 \%$ a região ombro, $9 \%$ a região lombar e todos membros inferiores. Riihimaki (1991) apud Kilesse (2005) mostrou resultados de pesquisas que indicaram que as vibrações que os motoristas estão expostos, associadas com a postura sentada prolongada, levam a dor e lesão na região lombar.

Atualmente, muitas pesquisas têm sido realizadas mostrando o aumento de doenças ocupacionais e dores muscoesquelética que acometem os trabalhadores. Bly e Richardson (1986) apud Queiróga e Michels (1999) afirmam que os trabalhadores que sentem dor se tornam menos produtivo no trabalho se comparado aos indivíduos que não sentem dor.

Um estudo realizado por Vuori (1995) relata que a dor no ombro e na região do pescoço vem crescendo nos trabalhadores que executam suas atividades na postura sentada devido à tensão e sobrecarga da musculatura dessas regiões. Isso por causa das exigências durante as trocas de marchas, mesmo com a evolução tecnológica nos câmbios dos caminhões, pode-se observar a presença de dor nos ombros, principalmente no ombro 
direito. Os fatores de esforço físico no local de trabalho foram avaliados qualitativamente e apresentados no Gráfico 7.

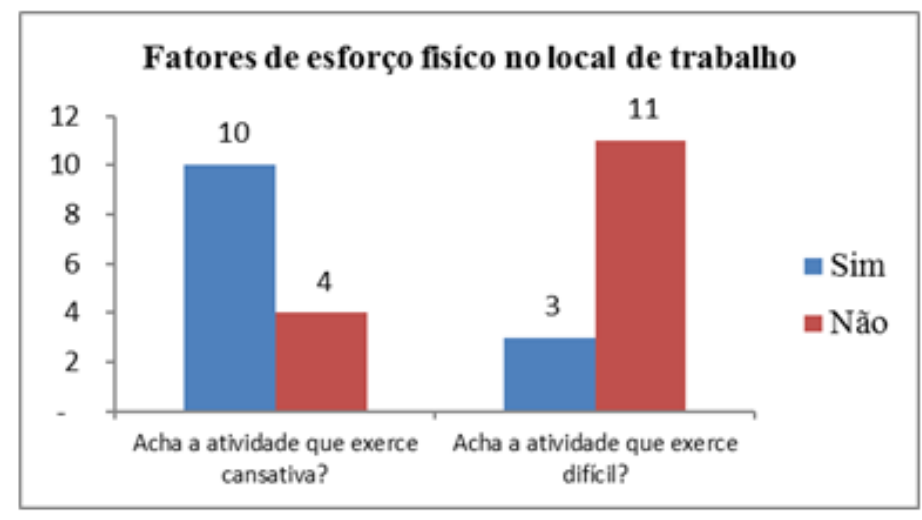

Gráfico 7 - Percepção do esforço físico no local de trabalho. Fonte: Elaboração própria (2017).

Pode-se observar no Gráfico 7 que 10 motoristas consideram a atividade que exerce cansativa e 3 motoristas acham essa atividade difícil de ser exercida, percepções essas que vão ao encontro do que Kilesse (2005) descreve como algumas exigências da atividade do motorista: manter a atenção contínua, analisar e interpretar as informações fornecidas pelo veículo, e eles devem ser ter uma audição e uma visão acuradas, movimentos coordenados e raciocínio rápido para executar a tarefa de condução de um veículo. Dessa forma, o autor afirma que a profissão de motorista é desgastante e estressante, pois além da exigência mental requerida em conjunto ao esforço dos órgãos sensoriais, fundamentais para essa profissão, esses profissionais devem manter-se, continuamente, em estado de alerta e atenção.

O Gráfico 8 mostra a correlação existente entre as variáveis do estudo como satisfação em exercer a atividade de motorista e sugestões de melhoria.

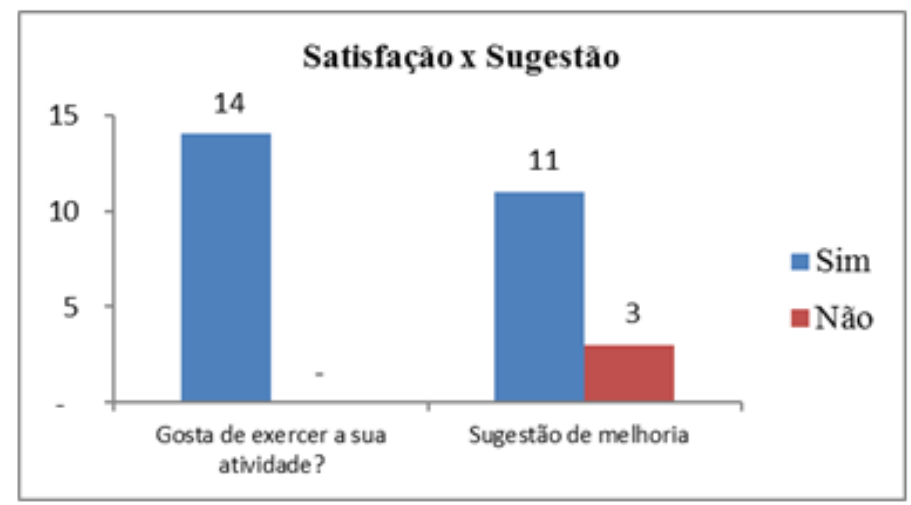

Gráfico 8 - Satisfação X Sugestão.

Fonte: Elaboração própria (2017).

Observa-se no Gráfico 8 que todos os motoristas gostam da atividade que exercem e quando questionados sobre a sugestão de melhoria, 11 motoristas quiseram opinar sobre 
possíveis sugestões, conforme apresentado no Gráfico 9.

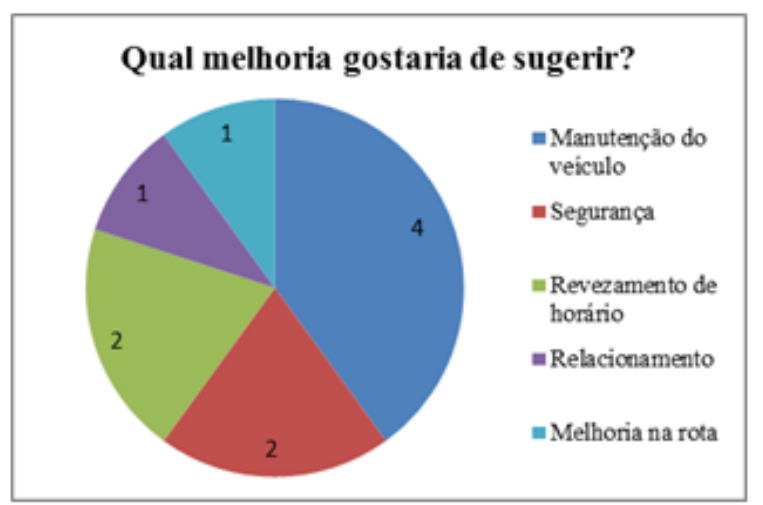

Gráfico 9 - Sugestões de melhoria.

Fonte: Elaboração própria (2017).

Por fim, por meio do Gráfico 9 observa-se que melhorar a manutenção do veículo, seja ela corretiva ou preventiva, foi a sugestão mais indicada pelos motoristas que quiseram opinar sobre sugestões de melhoria. Em seguida, dois motoristas sugeriram maior segurança, relacionada à segurança pública pois esses sofreram tentativas de assalto e suborno recentemente durante sua jornada de trabalho; outros dois motoristas sugeriram revezamento de horário. Foi também sugerida melhoria na rota e no revezamento de horário; e apenas um motorista sugeriu melhoria na rota, mas não soube indicar qual melhoria poderia ser realizada.

Gouveia et al.( 2012) afirma que a preocupação com a Qualidade de Vida no Trabalho (QVT) por parte das organizações vem crescendo, inclusive no Brasil, sendo portanto um diferencial estratégico cujo objetivo é melhorar a satisfação dos trabalhadores e consequentemente a produtividade da empresa. Esses autores explicam que os trabalhadores motivados, bem remunerados e competentes apresentam um maior desempenho nas suas atividades. Rossi et al. (2010) descreve que trabalhadores com baixo desempenho e baixa qualidade de produção, ao invés de mostrar seu melhor desempenho, passam a praticar mais erros e tornam-se menos precisos.

\section{CONCLUSÃO}

O transporte modal rodoviário é de extrema importância, justificando estudos recentes com os profissionais que exercem a atividade de motorista de caminhão, atuando no transporte de cargas. Os riscos ergonômicos atribuídos a essa profissão requer uma análise ergonômica para avaliar o posto de trabalho e as condições de trabalho de maneira criteriosa.

Conclui-se assim que o posto de trabalho do motorista de caminhão analisado possui assentos confortáveis e todos esses dispõem das regulagens necessárias; o projeto (design) da cabine dos veículos promove boa visibilidade, são de fáceis acessos e com tamanho adequado; as informações contidas no painel e displays foram consideradas organizadas e de fácil leitura.

Pode-se concluir que a atividade de motorista e realizada com combinações dos 
movimentos dos membros superiores e inferiores, associados a constantes rotações do pescoço e inclinações no tronco superior, ocasionando sobrecarga na coluna vertebral. Os movimentos repetitivos no membro superior, juntamente com o ambiente insatisfatório causa sobrecarga muscular levando a dor e fadiga muscular. A dor foi uma característica presente em 11 entrevistados, classificando-a como moderada e com tempo acima de seis meses, levando à cronicidade do quadro.

Portanto, em resposta ao terceiro objetivo desse estudo em relação à percepção dos motoristas quanto aos riscos ergonômicos inerentes a sua atividade, pode-se dizer que essa foi unânime e bem identificada. Quanto aos fatores ambientais os motoristas assinalaram o calor excessivo dentro da cabine do caminhão e a ausência de ar condicionado, visto que, a elevada temperatura prejudica o desempenho do motorista, ficando sonolento ou até mesmo irritado e apresentando baixa produtividade. Outro item verificado foi presença do ruído intenso, que também pode levar a queda da produtividade e até mesmo a Perda Auditiva Induzida por Ruído (PAIR).

Por fim, foi observada a satisfação dos motoristas em relação a exercer sua profissão e a adequação da iluminação. Nesse aspecto, como proposta para futuras pesquisas, sugerese a realização de um novo estudo para avaliar os riscos ergonômicos da função de motorista de caminhão quantitativamente; acrescentando a pesquisa o levantamento antropométrico dos motoristas e fazendo a medição da intensidade do ruído e da vibração ocupacional e da temperatura interna da cabine.

\section{REFERÊNCIAS BIBLIOGRÁFICAS}

BATTISTON, M.; CRUZ, R. M; HOFFMANN, M. H. Condições de trabalho e saúde de motoristas de transporte coletivo urbano. Revista Estudos de Psicologia. P. 333-343. 2006.

COUTO, H. A. Ergonomia aplicada ao trabalho manual: manual técnico da máquina humana, V. I. Belo Horizonte: Ergo Editora Ltda, 1995.

COUTO, H. A. Ergonomia Aplicada ao Trabalho: conteúdo básico: guia prático. Belo Horizonte: Ergo Editora Ltda, 2007.

FARIA, A. C. M. Aspectos ergonômicos a serem analisados em motoristas de ônibus urbanos. Faculdade Ávila: Centro de estudos avançados e formação integrada. Goiânia, 2013.

GOUVEIA, A.; FAGUNDES, C. R.; MACÊDO, S. S.; CASA JÚNIOR, A. J.; CASA, N. 1. L.; CRUZ, R. S. Análise da qualidade de vida no trabalho em caminhoneiros de uma indústria petrolífera. Revista eletrônica Saúde e Ciência, V.II, n. 02, ISSN 2238-4111, 2012.

IIDA, I. Ergonomia: projeto e produção. São Paulo: Edgard Blücher Ltda, 2005.

INSTITUTO DA MOBILIDADE E DOS TRANSPORTES. Disponível em:<www.imtt.pt/ sites/IMTT/Portugues/Paginas/IMTHome.aspx >. Acesso em: 02 abr. 2016.

KILESSE, RENAN. Fatores ergonômicos em posto de trabalho de motorista de 
caminhão. Viçosa, MG: UFV, 2005.

KROEMER, K. H. E; GRANDJEAN, E. Manual de Ergonomia: adaptando o trabalho ao homem. 5 ed. Porto Alegre: Bookman, 2005.

QUEIRÓGA, M. R. Incidência e localização de sintomas de dor em motoristas de ônibus na cidade de Londrina. Revista Brasileira Saúde Ocupacional. V.27: 121-32, 2002.

ROSSI, A. M.; PERREWE, P. L.; SAUTER, S. L. Stress e qualidade de vida no trabalho: perspectivas atuais da saúde ocupacional. Editora: Atlas, 2007.

SANTOS, C. M. C.; OLIVEIRA, S. K. R.; GONÇALVES, J. S.; OLIVEIRA, L. P.; SALDANHA, M. C. W. Levantamento das demandas ergonômicas dos motoristas dos circulares de uma universidade federal: um estudo de caso. XXIX Encontro Nacional de Engenharia de Produção, Salvador, 2009.

SEBASTIÃO, B.A.; MARZIELE, M.H.P.; ROBAZZI, M.L.C.C. Uma revisão sobre efeitos adversos ocasionados na saúde de trabalhadores expostos à vibração. Revista Bahiana de Saúde Pública. Salvador, 2007.

SILVA, L.R., MENDES, R. Exposição combinada entre ruído e vibração e seus efeitos sobre a audição de trabalhadores. Revista de Saúde Pública; 39(1):9-17; 2005. Disponível em: www.fsp.usp.br/rsp Acesso em: 12 abr. 2016.

SUTER, A. H. Naturaleza y efectos del ruído. Enciclopedia de salud y seguridade en el trabajo. Disponível em: <http://www.insht.es/InshtWeb/Contenidos/Documenta cion/TextosOnline/EnciclopediaOIT/tomo2/47.pdf>. Acesso em: 02 abr. 2016.

VUORI, I. Exercise and physical health: Musculoskeletal health and functional capabilities. Research Quarterly for Exercise and Sport; v. 66, n. 4, p. 276-285, 1995. 